\title{
Basic Robotecnical Platform for Implementation of Accurate Farming Technologies
}

\author{
N. I. Tchernyshev' ${ }^{1}$, O. E.Sysoev ${ }^{2}$, D. B. Solovev' ${ }^{3}$ E. P. Kiselyov ${ }^{4}$ \\ ${ }^{1,2}$ Komsomolsk-on-Amur State University Russia, 681013, Komsomolsk-on-Amur, Lenin Ave, 27, Russia \\ ${ }^{3}$ Vladivostok Branch of Russian Customs Academy, 690034, Vladivostok, Strelkovaya St., 16, Russia \\ ${ }^{4}$ Far Eastern Scientific Research Institute of Agriculture, 681013, Komsomolsk-on-Amur, Lenin Ave., 27, Russia
}

\begin{tabular}{l} 
Article Info \\
\hline Article history: \\
Received Feb 03, 2018 \\
Revised Jun 14, 2018 \\
Accepted Oct 08, 2018 \\
\hline
\end{tabular}

\section{Keywords:}

Bridge system

Ecology of agriculture

Energy saving

Point supports

Precision farming

Robotization of technological

processes

Self-propelled platform

\begin{abstract}
Improvement of modern technical systems and technologies. Increasing the productivity of modern agricultural machines with increasing their weight, which leads, in the course of their work, to a significant compaction of the soil. The heterogeneity of the soil, as a bearing surface, causes not adjustable fluctuations in the workplace, which makes automation of the application of robotics more difficult. Modern solutions to the problems of reducing the negative impact on the soil, increasing the permeability of aggregates due to the reconstruction of the propulsors do not give the proper effect. More cardinally solve these problems, as well as the ability to implement automation and robotics bridge systems such as $\mathrm{ABAC}$, moving along rail tracks, AASP on vertical piles and point gravel-halide supports with concrete platforms. The most promising of these is the AAS platform, which is a 30x10 m bridge structure that moves by step-by-step extension, the beams onto 3 subsequent pads located $10 \mathrm{~m}$ away. After entering the new position of the bridge platform, along the long 30-meter span beams Moves the worktechnological module with a set of working elements, performing the programmed operations. Thus, in the AASP bridge system under consideration, the soil area subjected to compaction at reference points is just over $1 \%$ of the $70 \%$ protraction of modern machines. Compared to the ABAC system, moving along railways, the equipment of point supports is much less expensive and requires insignificant operating costs. At the same time, the rigidity of AASP design ensures stable operation of technological mechanisms in a programmed robotic mode with a minimum of unproductive energy costs associated with movement.
\end{abstract}

Copyright $@ 2018$ Institute of Advanced Engineering and Science. All rights reserved.

\section{Corresponding Author:}

N. I. Tchernyshev,

Komsomolsk-on-Amur State University,

Russia, 681013, Komsomolsk-on-Amur, Lenin Ave, 27, Russia

Email: fks@knastu.ru

\section{INTRODUCTION}

Perfection of modern machine systems and technologies of agriculture practically exhausted their potential. As N. Krasnoschekov points out (1) "any technique and technology has a limit of its growth and if not to move to a new technical and technological level, further investments in existing machine-technical (technogenic) forms do not yield returns" [1]. The main point in the problem of a fundamentally new approach to the philosophy of mechanization of agriculture is the exclusion from the function of the soil cover as the main means of production of its part in the form of a bearing surface for the movement of energy resources that ensure the performance of technological operations with the help of working organs. 
Increasing the productivity of modern agricultural machines is usually associated with an increase in their weight, which leads, in the course of their work, to a significant compaction of the soil, a decrease in its biological activity, destruction of the structure and, ultimately, a decline in fertility.

The soil, as a bearing surface, is extremely heterogeneous medium in terms of physical parameters, which causes non-regulated fluctuations in loads on the working elements, as a result of which the accuracy of the specified technological parameters (depth of seeding, plant nutrition, norms and doses of fertilizers, chemicals protection of plants, etc.). At the same time, the possibilities and efficiency of introducing automation equipment, robotics into production are sharply reduced. The use of soils as a bearing surface, especially in the period of increased moisture, causes significant costs for the movement of machines and aggregates.

Modern solutions to the problems of reducing the negative impact on the soil, increasing the permeability of the aggregates due to the reconstruction of the propellers (twin, sprocket wheels, pneumaticgusenechnye propulsors, lengthening the wheel axes, etc.) do not give the proper effect. To more radical solutions to the problem of reducing the negative impact on the soil, increase the passability and reduce unproductive energy costs, create conditions for the introduction of automation and robotics can be attributed bridge systems, moving on rails $\mathrm{m}$ tracks, vertical piles and gravel-point support with galichnym betonirovannymmi sites. Of the bridge systems mentioned above, the last of the listed agrotechnical automated self-moving platform (AASP) is of particular interest in the possibilities of practical realization.

The AAS platform is a bridge structure made of $\mathrm{P}$-shaped sections of approximately $30 \times 10 \mathrm{~m}$ in size. In short hollow 10-meter profiles, the supporting 20-meter structures move along the rollers, which are step-by-step, laid on 3 point pads located $10 \mathrm{~m}$ away. support beams-propulsors occurs in the elevated, due to the vertical hydraulic cylinders, the state of the platform. After the hydraulic cylinders are relaxed and the support beams are laid on the platforms, a bridge platform moves along them, where a technological module moves along a long 30-meter span with a set of operating elements for the execution of the programmed operations.

\section{PROBLEMS OF THE MATCHED MACHINE TECHNOLOGIES}

The needs of plants in the conditions of life (water-air regime of the soil, the feeding area, the depth of seeding, the norms of fertilizers, irrigation, pesticides, etc.) have been thoroughly studied by agricultural science. They are set out in various regulatory and technological documents, most of which are implemented with the help of agricultural machinery.

Modern varieties and hybrids have a sufficiently high potential in terms of immunity and productivity. However, it is only partially realized. In agriculture, the law of the equivalence of all factors of life acts, while the level of productivity determines not the average size of available resources, and the smallest security by one or the other factor. Therefore, for the formation of a high yield, timely and highquality performance of the whole complex of agrotechnical measures is necessary.

The support for machines and mechanisms used in agriculture is the object of processing itself - soil, which is not homogeneous in physical terms. Working in such conditions, modern agricultural machines are not able to withstand the given parameters of the technology of cultivation of agricultural crops [2]. The constantly changing load on the working elements and propellers of the machine causes them to slip and lateral displacements, which leads to uneven placement of seeds, damage to plants during processing, losses during harvesting.

The purpose of our study is to consider some technical solutions for the modernization of modern and promising agricultural machines and systems that ensure the timely and high-quality implementation of standards for livelihoods of cultivated plants at a high ecological level, qualified as precision (precision) agriculture to increase yields and quality of products condition of automation of technological processes, reduction of material consumption and production costs.

One of the greatest shortcomings of modern machine technologies is the destruction of soil structure and its compaction caused by agricultural machinery, which causes a significant reduction in yield. In the work of A. Skuratovich [3], it is noted that a decrease in yield causes an increase in the bulk density, even by $0.01 \mathrm{~g} / \mathrm{cm}^{3}$, and when soil is compacted by wheel tractors of $2 \mathrm{~kg} / \mathrm{cm}^{2}$ force, the collection of potato tubers decreases by more than $50 \%$, the yield of cereals - on $8-13 \%$. The yield level basically determines the conditions for the development of the root system and, to a large extent, the degree of soil compaction in the process of cultivation of crops. In particular, 4 compaction zones [3] are installed for the potato [3]: normal compaction (up to 1.0 MPa), medium seal (1.1-2.5 MPa), strong compaction (2.6-4.5 $\mathrm{MPa}$ ) and reconsolidation above $4.5 \mathrm{MPa}$ ).

The study of the level of soil compaction during crest planting of potatoes, including the cutting of crests, planting, three interrow processing, preparation for harvesting (cutting of the foliage), showed that 
after the completion of the listed works of the technological process, the degree of density above the mother tuber $(0-20 \mathrm{~cm})$ was within In this zone, the most intensive development of the root system and tuber formation was noted, in the zone of strong compaction $(20-50 \mathrm{~cm})$ these processes were less intense. In the compaction zone (deeper than $50 \mathrm{~cm}$ ), the development of the root system and the formation of tubers were not observed [4].

An increase in density leads to the destruction of the soil structure, a decrease in porosity, which causes a deterioration of the air-water regime, suppression of soil biota, deterioration of the food regime and, in general, fertility $[5,6,7]$.

Intensification of modern farming is associated with multiple passes through the field of agricultural machines and vehicles during the vegetative period of plants. At the same time, the increase in their productivity is due to greater power, the increase of which is accompanied by a significant increase in mass. So, for 15-20 years the mass of agricultural tractors increased from 7-14 tons in CT-7 and K-701 to 16-20 tons in K-744 P2, K-744 P3. The energy-consuming tractors T-150, K-700, T-4, DT-175, etc., widely applicable in Russia's agricultural production, are 2-3 times more massive than MTZ-80, MTZ-82, T-74, DT75 , used in 1970-90, which leads to an additional increase in the load on the soil cover and its compaction (as shown in Table 1 [4].

Table 1. Soil Compaction at Work of Tractors of Different Brands

\begin{tabular}{cccc}
\hline Tractor brand & Weight of tractor, $\mathrm{t}$ & $\begin{array}{c}\text { Specific thruster pressure, } \\
\mathrm{kg} / \mathrm{cm}^{2}\end{array}$ & $\begin{array}{c}\text { Soil compaction at one } \\
\text { tractor pass, } \mathrm{g} / \mathrm{cm}^{3}\end{array}$ \\
\hline D1-75m & 6,3 & 0,5 & 1,15 \\
T-4A & 7,9 & 0,5 & 1,20 \\
MT3-80 & 2,9 & 1,2 & 1,32 \\
T-150K & 6,3 & $1,4-2,0$ & 1,35 \\
K-701 & 7,9 & $1,5-2,5$ & 1,42 \\
\hline
\end{tabular}

Modern intensification of agriculture, as a rule, is based on increasing the multiplicity of technological processes. Cultivation of the crops of continuous sowing (cereals) is 7 passes after plowing (fertilization, fertilization in the soil, sowing, packing, pre-emergence, sprouting, chemical treatment), on row crops - up to 9 passes, which causes significant soil compaction as shown in Figure 1.

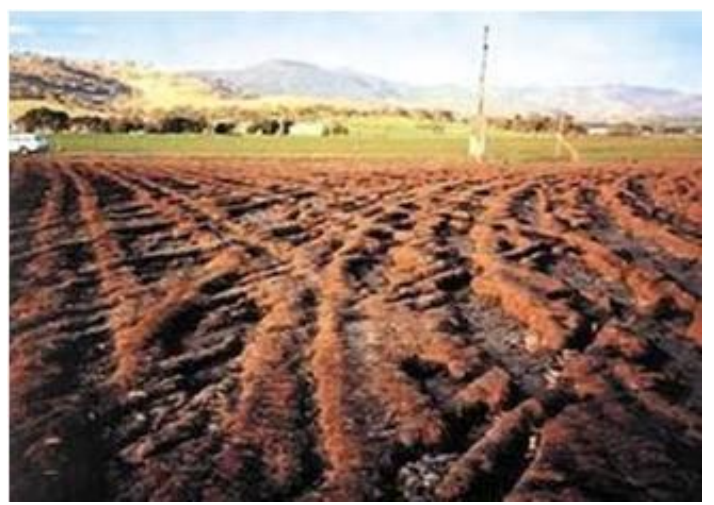

Figure. 1. Field appearance after the appearance of traces of equipment, as a result of weathering [5]

In the Amur region, barley cultivation is associated with 12 times the tractor's passage through the field, as a result of which only $33 \%$ of its area remains uncompacted. At the same time, a three to fivefold seal reduces the yield of the crop by 0.15-0.22 t/ha [8].

According to N.A. Karapetyan. [9], at 4-8 passes the soil density in the arable horizon reaches a threshold value of $1.65-1.70 \mathrm{~g} / \mathrm{cm}^{3}$, the porosity drops to a critical level, and to the 10th pass decreases to a very low value - less than $40 \%$. Depending on the degree of compaction, a significant decrease in yield is observed. Thus, in spring wheat, on uncompacted soil, it was 2.22 tons/ha; on slightly compacted - 1.93 t/ha; medium-compacted - $1.22 \mathrm{t} / \mathrm{ha}$; highly compacted-0.99 t/ha; overcrowded - 0,92 t/ha.

Soil is the main medium that provides growth and development of agricultural crops and simultaneously performs the function of a bearing surface for tractors and machines. Being extremely 
heterogeneous in the conditions of periodic wetland, the soil surface is characterized by a wide spread of parameters that determine the stability of the operation of power tools and mechanisms (resistivities in the movement of tractors and tools, viscosity, density, permeability, etc.). For example, the rolling resistance coefficient, depending on the surface properties and the motion characteristics, ranges from 0.08 to 0.25 [10].

Reducing the load-bearing capacity of soils in conditions of their waterlogging leads to loss of patency of tractors, and at the same time to violations of agrotechnical terms of work. The heterogeneity of physical characteristics of soils causes significant deviations from the specified parameters for the performance of technological operations by the working bodies.

Thus, modern systems of agricultural machines do not provide for the performance of the parameters stipulated by the technologies, are very energy-intensive and have low efficiency, are insufficiently adapted for the implementation of precision farming systems.

\section{PRECISE FARMING AND THE PRINCIPLES OF ITS SOLUTION}

The intensity of treatment, the use of powerful and heavy machines leads to compaction and dispersion of soils, the development of erosion processes, the loss of significant areas of agricultural land. To solve these and a number of other problems of sustainable provision of plants with a complex of life factors and high productivity, a number of technologies and machines are proposed, united by the concept of "precise farming":the problem of their implementation can be conditionally divided into three blocks: the determination in the soil and plants in the vegetation period of the provision of life elements, the need for mineral fertilizers, chemical means of protection against diseases and pests, followed by fixation in electronic memory; reduction of structure destruction and soil compaction, creation of optimal water-air regime of soil in order to provide conditions for soil macro- and microorganisms, reduction to the maximum permissible concentration (MPC) of chemical elements of introduced mineral fertilizers and plant protection products against pests, diseases and weeds; exact execution of scientifically grounded technological parameters (terms of work, depth of seeding, optimal feeding area, timely loosening of the soil, mechanical removal of weeds, necessary for the state of plants for fertilizing during the growing season, high-quality harvesting).

Today, the world is actively searching for optimal solutions to these problems. With regard to the solution of the problem of "targeted" differentiated provision of plants with elements of mineral nutrition, taking into account the actual situation on each individual site, a number of developments are proposed to improve the methods of agrochemical analysis of soils and plants on their basis the construction of maps of precision farming.

In many countries of the world, instead of agrochemical soil analyzes, a method of estimating through yields of individual sections of the field is used, with subsequent fixation of the situation in computer memory. On the basis of this information, fractional addition of the necessary mineral elements is carried out for next year's crops. At a higher level, this problem is solved with the help of an optical instrument from the English company Challeng Agriculture, capable of determining by spectral analysis the content of food elements in plants and the degree of their provision with the fixation of the information obtained in electronic memory $[11,12]$.

To solve the problems of the second group, a number of mechanisms and systems are proposed for sealing machines and mechanisms of the soil and the associated destruction of its structure, maintaining the water-air regime of soils and optimal conditions for biocenoses. For example, in order to reduce pressure on the soil, the running parts of power machines and agricultural implements are improved by using twin and built-in tires of wheeled tractors, which opens the door to agricultural work in conditions of waterlogging. Significant, several times less load, compared with conventional wheeled tractors, provide energy with crawler drives [3]. In the All-Union Institute of Mechanization of Agricultural Production, tractors were developed and tested on pneumatic caterpillar propulsors, the use of which provided good results [13]. To a certain extent, the problem of reducing the specific load on soil is being replaced by modernized crawler drives $[14,15]$.

To reduce the area of the tractors and machines subjected to pressure, various solutions are proposed for regulating the operation of agricultural machinery through the movement of machines on a constant track, as well as lengthening the wheel axles. This allows you to reduce the footprint on the field from $80 \%$ with conventional technology to $14 \%$. This approach is widely used in Australia, where about 1 million hectares are cultivated using a constant gauge. Technical solutions to the problem of constant track and equipment with enlarged inter-gauge axes are presented in the survey by A. Skuratovich [3], which considers various variants of agricultural machines with enlarged inter-wheel (caterpillar) axes up to devices qualifying as bridge units, such as David Dowler tractor with span $12 \mathrm{~m}$, equipped with laser guidance system. Israeli scientists in 1996 developed a tractor with a span of $5.8 \mathrm{~m}$ and a ride height of $1.8 \mathrm{~m}$. But machines of this type have a significant drawback associated with large turning areas at the edge of the field, insufficient for 
basic soil cultivation by pulling force, insufficient permeability. Due to the heterogeneity of the bearing capacity of the soil, the accuracy of the execution of technological operations by machines of this class remains low $[16,17]$.

\section{BRIDGE FARMING AS AN ASPEN FARMING}

In our view, the decrease in the negative impact on soil, the exact implementation of agrotechnical parameters, the reduction of energy costs, the increase of labor productivity and the solution of the problems of accurate farming are largely provided by bridge farming systems. The requirements for exact farming from known versions of bridge farming systems are to a certain extent answered by the automated bridge agrotechnical complex (ABAC) [18]. Its main features include the bridge system, on the whole width of which the working elements are mounted, and the rails that support the complex. The technological process is carried out during the movement of the complex.

The rigid basis of the $\mathrm{ABAC}$ system in the form of rails creates conditions for the use of automation, which ensures timely and accurate implementation of the specified technological parameters, preservation and improvement of soil fertility, and also to a large extent the solution of problems of land use ecology.

With all the advantages, the ABAC complex has a number of significant shortcomings, the main of which is high metal consumption for the arrangement of rail tracks (about 17.5 tons/ha), significant costs for their installation, high material consumption (sleepers, rail fastenings, etc.), while rejecting up to $10 \%$ of arable land. In the bridge system, where reinforced concrete piles serve as support for the movement, the equipment of the landfill will be quite complex, as well as the high cost of installing reinforced concrete piles. Deep freezing of the soil at 3.0-3.5 $\mathrm{m}$ in some years can cause a height shift and a horizontal deviation, which will reduce the accuracy of the technological norms [18].

Closer to the optimal version of the bridge system can be an automated agrotechnical self-propelled platform (AASP), protected by patent No. 2636472 as show in Figure 2 [19]. Technical solutions, incorporated in its design, greatly improve the well-known agrotechnical systems. Providing such advantages of bridge systems to modern machine and tractor complexes, as the creation of conditions for precise farming (targeted, strictly standardized in time, volumes and parameters of providing plants with growth factors), a significant increase in productivity and attractiveness of labor due to robotic processes, high profitability, on the soil as a biological environment, the preservation of the optimal water-air regime and the structure of the soil cover, the proposed system MA provides a fundamentally different system of propellers and bearing supports as shown in Figure 2.

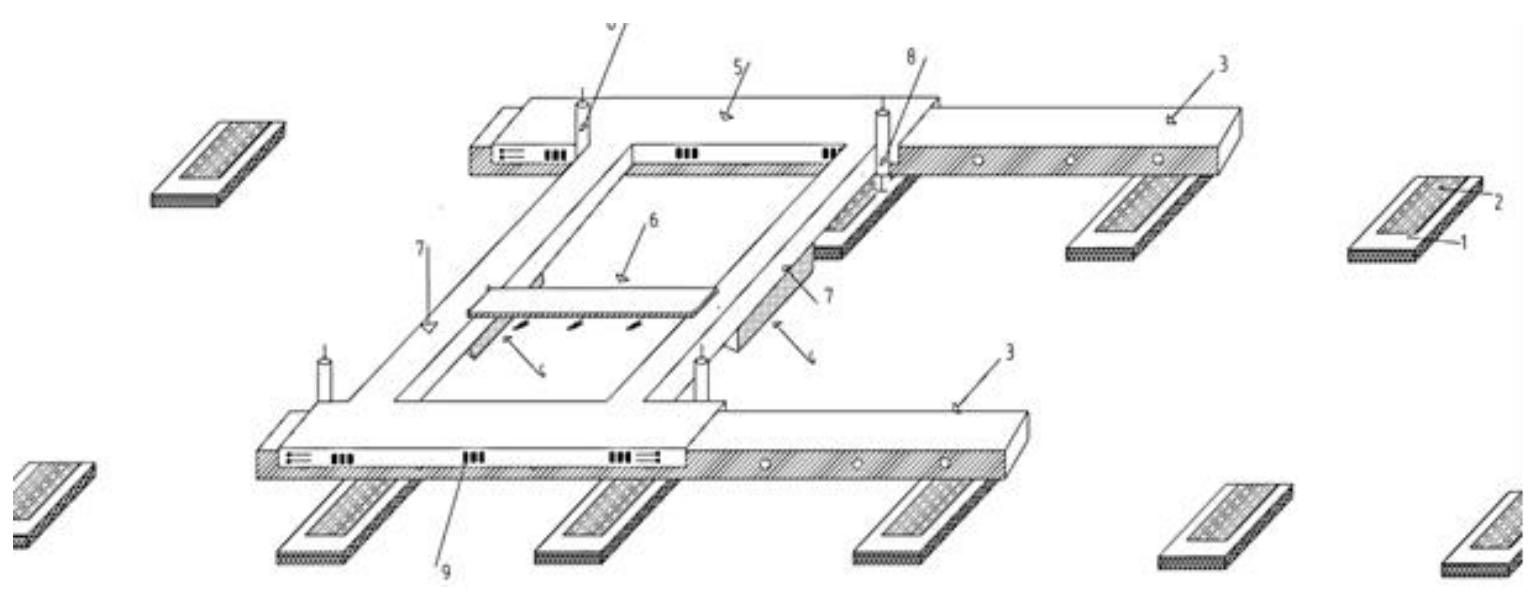

Figure. 2. The basic structure of the AASP platform: 1 - crushed stone cushions; 2 - concrete beams; 3 longitudinal longitudinal beams; 4 - cross-section beams; 5 - platform; 6 - technological module; 7-transverse beams (long); 8 - hydraulic cylinders; 9 - ratchet mechanism for moving inner beams

The width of the bridge complex is $30 \mathrm{~m}$, length - $10 \mathrm{~m}$. It is made of reinforced beams. Short 10meter beams are hollow, they have mobile 20-meter beams (3), which are step-by-step advanced by $10 \mathrm{~m}$ and serve as a kind of rails on which the platform moves to a new position. Support for rail beams are concrete blocks (2), lying on crushed stone pillows (1). On the long transversal beams (7) the technological module (6) moves, which in the automated mode performs the programmed technological operations as show in Figure 3.

BEEI, Vol. 7, No. 4, December 2018:522-528 


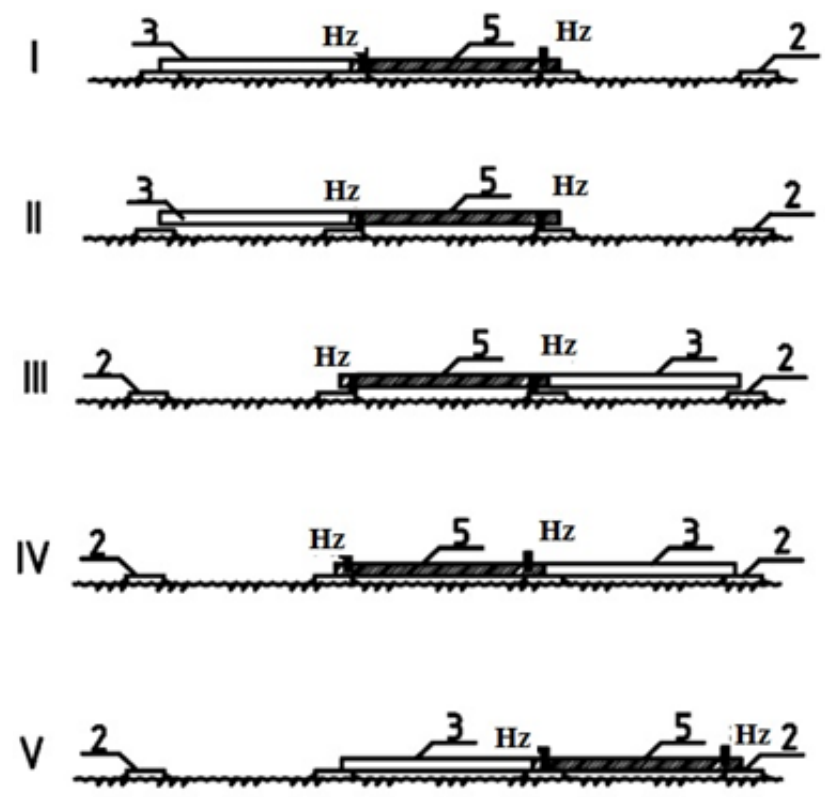

Figure 3. Scheme of moving the platform: I - the starting position; II-V - consecutively replaced positions. hc - hydraulic cylinders, 5 - AASP platform of the profile of the U-shaped section, 3 - mobile beams, 2 - supports

To move the inner beams from the original (I) to the new position, the platform frame with the hydraulic cylinders (Hz), supported by the concrete blocks 2 as show in Figure 3, is raised (position II), as a result of which the inner beams 3 are unloaded and by means of special ratchet mechanisms move to position III, cylinders (Hz) relax, inner beams lie on concrete supports 2 (position IV). Accordingly, the platform rests on beams equipped with rollers. With the help of the ratchet mechanism, the platform rolls over the rollers to position $\mathrm{V}$, technological module 5 performs the specified operation, after which the cycle (II-V) is repeated.

The proposed system is solved in a fundamentally new way: the way of movement involves step-bystep extension of the beams along which the platform with the technological module moves, the stability of the system is provided by concrete blocks rigidly oriented on the terrain, which allows the technological module to reach each plant with high accuracy; mode of precision farming at a high ecological level, the proposed system allows to fully automate the process of crop cultivation in the field th cultures.

\section{CONCLUSION}

The proposed agrotechnical automated automated self-moving patented platform (AASP) [20] with respect to a similar bridge system, the closest in construction, ABAC [18], is distinguished by a system of movement along the field. To move the ABAC system, a rail track arrangement is provided at a width of 30 meters that bridge system requires 17.5 tons per hectare (R-50 700 thousand rubles) in the form of rails. Installation and maintenance of 330 meters of rails per hectare requires significant material and labor costs (400 thousand rubles/ha.). The bridge system AASP moves with the help of step-by-step movement of the beams - the supports are based on concrete slabs $1 \times 1 \times 0.25$ meters laid on gravel-crushed stone pillows $2 \times 2 \times 0.4$ meters, while the estimated concrete consumption is $8.5 \mathrm{~m} 3 /$ ha (50 thousand rubles ./ha), gravel or crushed stone $50 \mathrm{~m} 3 / \mathrm{ha}$ (100 thousand rubles/ha). Thus, the estimated cost of polygon equipment in the ABAC analogue will be 1.1 million rubles, which is an order of magnitude more expensive than for AASP (0.15 million rubles). Since these systems are searchable, payback indicators are difficult to estimate. The study of literary sources showed the absence of such agrotechnical systems in world practice.

\section{REFERENCES}

[1] Goryachkin. V. P., Agricultural Mechanics. Part I. VP Goryachkin. Moscow: Kn. publishing house. Peter. s.-. Acad., 2009; 200.

[2] Alekseichik. N.A., Use of the machine-tractor park on peat-bog soils. Kolos, 2008; 103. 
[3] Burlaka.V.V., Biological foundations of plant growing on the waterlogged soils of the Far East. Khabarovsk, 2017. 210.

[4] Skuratovich. A. Do not press the guys! Do not press. Triz-pro: Effective solutions. 2006; 2: 23-31.

[5] Lachuga.Yu. F. ,On the strategy of machine and technological support for the production of agricultural products in Russia for the period up to 2012. Strategy of machine and technological support for the production of agricultural products in Russia for the period 2008-2012 years. : materials of scientific-practical. Conf. Moscow. 2008; 8-18.

[6] Karapetyan.M.A., Improving the efficiency of technological processes by reducing soil compaction by running systems of agricultural tractors. dis. ... doc. those. Karapetyan Martik Arshaluysovich. Moscow, 2010: 305.

[7] Kostyuchenkov.N.V., Operational properties of mobile aggregates. Astana (Kazakh), 2010; 206.

[8] Adamchuk.V.V., Precise farming: a being and technological problems. Tractors and agricultural machines, 2003; 8: 44-52.

[9] Tom Schuldt Farming - October 28th, 2000. Tractor, http://knauer.homeip.net/farm/tractor.ipg

[10] 4WD Tractor Wheels, http://www.woldinc.com/4wd-tractor.htm]: John Deere 9R Series Tractors, http://www.deere.com/wps/dcom/en US/products/ equipment/tractors/four wheel drive tractors/9r 9rt series/9r 9rt series. Page?

[11] TRIZ-pro: Effective solutions in agriculture. Moscow: Kushnir, 2006. 2: 17-21.

[12] Zaytsev.S.D., Energy means on ultra-low pressure tires. Tractors and agricultural machines, 2006; 10: 12-21.

[13] Pneumotrack of the vehicle caterpillar. The author's certificate of the USSR №965869, http://patentdb.su/3-965869pnevmotrak-gusenicy-transportnogo-sredstva.html

[14] Tramline Farming Systems. Technical manual. Department of Agriculture Western Australia, GRDC project DAW 718. Bulletin 4607. Feb. 2004.

[15] Chamen W.C.T., Dowler D., Leede P.R., Longstaff D.J. Design, operation and performance of a gantry system: experience in arable cropping. Journal of Agricultural Engineering Research. 1994, 59: 45-60.

[16] Altshuller, GS Seeking new ideas: from insight to technology. Chisinau: Cartaya (Moldoveniaske). 1989: 5: 17-28.

[17] Wide Span CTF, WhatIs/Wide-Span-CTF.aspx, W.C.T. Chamen. A new methodology for weed control and cereal crop production based on wide span vehicles and precision guidance: BioTrac. P-51. http://www.ewrs.org/pwc/doc/2000_Elspeet.pdf .

[18] Satish Kumar.K.N., Sudeep.C.S., Robots for Precision Agriculture. Proceedings of the 13th National Conference on Mechanisms and Machines (NaCoMM07). IISc. Bangalore (India). 2007: 118-132.

[19] E.J.Van Henten. Cropscout - a mini field robot for research on precision agriculture. Agrotechnology \& Food Innovations Ltd.: A..A.Wageningen,The Netherlands.2015: 165-210.

[20] S. Blackmore, B. Stout, M. Wang, B. Runov., ROBOTIC AGRICULTURE -THE FUTURE OF AGRICULTURAL MECHANISATION? Proceedings of the 5th European Conference on Precision Agriculture Uppsala, Agrovej (Sweden). 2005: 321-332.

[21] Zhalnin, E. V. History of development and prospects for the introduction of bridge plant production, Tractors and agricultural machinery, 2002. 5: 23-30.

[22] Zhukov Yu. N. Automated bridge agrotechnical complex - ABAC. Sowers and keepers: Moscow: Contemporary. 1992: 345-387.

[23] D. B. Solovev Instrument current transducer for protective relaying systems Proceedings of the Dynamics of Systems, Mechanisms and Machines (Dynamics -2017), International Conference. Omsk. 2017: 1-5. [Online]. Available: http://dx.doi.org/ 10.1109/Dynamics.2017.8239511

[24] Chernyshev. N.I. et al., Bridge system as a basis for the implementation of point agriculture, Uchenye zapiski (Komsomolsk-on-Amur State Technical University). 2011; 1-1(5): 113-118.

[25] D. B. Solovev, et al., Novel active current transducers for diesel power stations, International Journal of Power Electronics and Drive Systems, 2016; 7(1):152-158. [Online]. Available: http://dx.doi.org/10.11591/ijpeds.v7.i1.

[26] D. B. Solovev, et al., Analysis of modeling of current differential protection, International Journal of Power Electronics and Drive Systems, 2015; 6(3): 423-428. [Online]. Available: http://dx.doi.org/10.11591/ijpeds.v6i3.7701.

[27] Chernyshev N.I., Sysoev O.E., Esipov M.Sc. Automated agrotechnical self-propelled platform (AASP) 2636472 (Patent). 2017. 